\title{
EMPREENDEDORISMO JOVEM: DA ESCOLA PARA O MERCADO DE TRABALHO
}

\author{
D. C. GOMES ${ }^{1 *}$, L. A. F. SILVA', M. F. D'ANJOUR ${ }^{2}$ e M. E. M. AÑEZ ${ }^{2}$ \\ ${ }^{1}$ Instituto Federal do Rio Grande do Norte \\ ${ }^{2}$ Universidade Federal do Rio Grande do Norte \\ danilo.cortez@ifrn.edu.br*
}

Artigo submetido em julho/2014 e aceito em novembro/2014

DOI: $10.15628 /$ holos.2014.2220

\section{RESUMO}

O empreendedorismo jovem apresenta-se como forma de inclusão de jovens no mercado de trabalho e em contrapartida é fator preponderante para promoção do desenvolvimento socioeconômico brasileiro (LIMAFILHO, SPROESSER, MATINS, 2009). Nesta perspectiva, o objetivo central desse artigo é discutir o ensino do empreendedorismo para os jovens utilizando como "case" o projeto "Empreendedorismo jovem: da escola para o mercado de trabalho" que buscou estimular os alunos do IFRN - Campus Currais Novos quanto à criação de novos negócios relacionados às suas áreas de formação técnica (alimentos e informática), através de uma série de atividades (visitas a empresas dos ramos de informática e alimentos; workshops e palestras; evento; seminários). Esse projeto buscou preencher uma lacuna muitas vezes encontrada no Campus quanto ao conhecimento prático das ações relacionadas à gestão empresarial e criação de novos negócios, bem como da participação mais efetiva das empresas nos eventos da instituição, como forma de dá oportunidade para que estes conheçam as potencialidades existentes nos cursos de informática e alimentos. Além do mais, os trabalhos desenvolvidos no projeto possibilitaram o despertar desses alunos quanto à criação de empresas. 0 projeto teve duração de sete meses, nos quais as diversas ações foram realizadas paulatinamente.

PALAVRAS-CHAVE: empreendedorismo, mercado de trabalho, IFRN - Campus Currais Novos

\section{YOUTH ENTREPRENEURSHIP: FROM SCHOOL TO LABOUR MARKET}

\begin{abstract}
Young entrepreneurship is presented as a way of including young people in the labor market and in the other hand is a leading factor to promote Brazilian socioeconomic development (LIMA-FILHO, SPROESSER, MATINS, 2009). From this perspective, the central aim of this article is to discuss entrepreneurship education for young people using as "case" the "Young Entrepreneurship: from school to the labor market" project that sought to encourage IFRN - Campus Currais Novos students regarding the creation of new business related to their high school technical areas (food and computer science). Through a series of activities such as visits to companies in the fields of computer science and
\end{abstract}

food, workshops and lectures; event; seminars; etc this project aimed to fill the gaps found at this campus regarding to the practical knowledge of the actions related to business management and new business creation as well as the more effective participation of business companies in the events of the institute in order to give opportunity to those who knows the potential that there is in computer and food technical courses. Moreover, works developed by this project enabled the awakening of these students to entrepreneurship. The project lasted seven months and several kinds of activities were promoted gradually..

KEYWORDS: entrepreneurship, labor market, IFRN - Campus Currais Novos. 


\section{INTRODUÇÃO}

O interesse no incentivo do estudo e da prática empreendedora dos jovens brasileiros se dá por vários motivos, especialmente "por ser, o Brasil, do ponto de vista demográfico, um país jovem e ser a juventude uma etapa de transição que processa a passagem de uma condição social mais recolhida e dependente a uma mais ampla" (UNESCO apud WAISELFISZ, 1998, p. 154). De acordo com Carreteiro (2001) o "conceito de projeto" mostra que o homem busca sua afirmação pela ação, sendo a prática profissional uma das dimensões centrais da juventude, pois o jovem busca afirmação pelo reconhecimento profissional.

Assim, levando em conta que entre 2008 e 2009 o SEBRAE ao realizar uma pesquisa para explicar a dinâmica do mercado, demonstrou que $49 \%$ das novas empresas duram até seis anos de funcionamento antes de falirem, ou seja, o que representa um índice elevado quando relacionado à criação dos novos negócios e as consequências da falta de gerenciamento ou mesmo despreparo dos gestores e empreendedores. Nesse sentido, a atividade empreendedora pode, por um lado, garantir realização a curto, médio e longo prazo, sendo um instrumento que potencializa novas ideias e negócios. Entretanto, se mal utilizado, essas ações "empreendedoras" podem gerar frustação.

Desse modo, os alunos dos Institutos Federais são orientados conforme suas grades curriculares, para uma formação integral e técnica diante das perspectivas e desafios atuais existentes no mercado de trabalho. De acordo com a Lei no. 11.892, de 29/12/2008 que institui a Rede Federal de Educação Profissional, criando os Institutos Federais, uma das finalidades destes é o incentivo e estímulo ao empreendedorismo. Assim, o projeto desenvolvido está totalmente alinhado às finalidades da instituição na formação dos alunos.

Todavia, nem sempre esses alunos enxergam oportunidades de criação de novos negócios de acordo com sua formação técnica e/ou não estão prontos para superar as dificuldades que surgirão no ingresso ao mercado de trabalho. Para Dornelas (2007), a experiência anterior no ramo ou atividade correlata é fator fortemente presente entre os empreendedores de sucesso, pois além da preparação técnica e profissional, em muitos casos, a experiência auxilia o empreendedor a conhecer o mercado, suas falhas e demandas, levando-o a perceber e aproveitar oportunidades. Nessa perspectiva, o projeto "Empreendedorismo jovem: da escola para o mercado de trabalho" buscou dá subsídios para que os alunos conhecessem e aprendessem práticas empreendedoras relacionadas às suas áreas de formação, a partir do contato com empresas locais e regionais, condicionando-os para um melhor entendimento das potencialidades existentes no ramo de negócio em que poderão atuar futuramente.

É fato que boa parte dos jovens sonha em ter o próprio negócio, como aponta algumas pesquisas publicadas em relatórios do Global Entrepreneurship Monitor - GEM, tal qual a que foi realizada em 2012 no Brasil, enfatizando que 44\% dos brasileiros entrevistados disseram preferir ter uma empresa ao invés de ter um emprego formal, ou seja, há um potencial significativo no Brasil para ações empreendedoras, principalmente quando se analisa a geração que está sendo inserido de algum modo no mercado.

Durante o projeto, além das visitas a empresas locais e regionais, como o Porto Digital em Recife/PE, esses subsídios também foram oferecidos através de uma série de outras atividades 
(workshops e palestras; evento; seminários). Entende-se que através do projeto com suas diversas atividades, a temática empreendedorismo tornou-se mais conhecida e certamente o interesse foi despertado entre o corpo discente, além do corpo docente que se interessou pelo assunto, inclusive sugerindo parcerias para eventos e projetos futuros.

\section{CONCEITUANDO EMPREENDEDORISMO}

O termo empreendedorismo surgiu entre a segunda metade do século XVIII e o início do século XIX com os economistas Richard Canttilon (1755) e Jean-Baptiste Say (1803). Ambos consideravam os empreendedores como pessoas que corriam riscos por investirem seu próprio dinheiro. Degen $(2009$, p. 6 ) ao comentar sobre a etimologia da palavra empreendedorismo diz:

\footnotetext{
O significado da palavra empreendedor deriva da palavra inglesa entrepreneur, que, por sua voz, deriva da palavra entreprendre, do francês antigo, formada pelas palavras entre, derivada do latim inter - que significa reciprocidade - e preneur, derivado do latim prehendere - que significa comprador. A combinação das duas palavras, entre e comprador, significa simplesmente intermediário.
}

Filion (1999) considera o empreendedorismo como um campo em que se estuda a atividade empreendedora. Segundo (Dornelas, 2012, p.28): “empreendedorismo é o envolvimento de pessoas e processos que, em conjunto, levam a transformação de ideias em oportunidades. E a perfeita implementação destas oportunidades leva à criação de negócios de sucesso". Mas o próprio autor ainda assume que para o termo "empreendedor" existem muitas definições, uma das mais antigas é a de (Joseph Schumpeter, 1949 apud Dornelas, 2012, p. 28): “O empreendedor é aquele que destrói a ordem econômica existente pela introdução de novos produtos e serviços, pela criação de novas formas de organização ou pela exploração de novos recursos materiais".

Destaca-se o termo inovação quando o assunto se relaciona ao empreendedorismo, pois segundo Drucker (2012, p. 25), "a inovação é o instrumento específico dos empreendedores, o meio pelo qual eles exploram a mudança como uma oportunidade para um negócio diferente ou um serviço diferente".

\section{O PERFIL DO EMPREENDEDOR}

Assim como para o termo empreendedorismo, na literatura disponível não existe um consenso sobre o perfil do empreendedor, no entanto, existem vários autores que apresentam características comuns para o mesmo. Dornelas (2007) cita as características de um empreendedor de sucesso como: são visionários; sabem tomar decisões; indivíduos que fazem a diferença; determinados e dinâmicos; otimistas e apaixonados pelo que fazem; bem relacionados; planejam; assumem riscos calculados; e são dedicados, entre outras qualidades.

Segundo Britto e Wever (2003) para o empreendedor cinco elementos são fundamentais em sua característica:

- Criatividade e inovação: empreendedores conseguem identificar oportunidades, grandes ou pequenas onde ninguém mais consegue notar;

- Habilidade ao aplicar esta criatividade: eles conseguem direcionar esforços num único objetivo; 
- Força de vontade e fé: eles acreditam fervorosamente em sua habilidade de mudar o modo como as coisas são feitas e têm força de vontade e paixão para alcançar o sucesso;

- Foco na geração de valor: eles desejam fazer as coisas da melhor maneira possível, do modo mais rápido e mais barato.

De acordo com Filion (1997) as características variam de acordo com as atividades que o empreendedor executa em uma dada época ou em função da etapa de crescimento da empresa. Mesmo assim, o mesmo autor acredita que dando uma olhada global na história dos empreendedores de sucesso de todos os tempos podem se notar o seguinte:

- tem um "modelo", uma pessoa que o influencia;

- tem iniciativa, autonomia, autoconfiança, otimismo, necessidade de realização;

- trabalha sozinho. O processo visionário é individual;

- tem perseverança e tenacidade para vencer obstáculos;

- considera o fracasso um resultado como outro qualquer, pois aprende com os próprios erros;

- é capaz de se dedicar intensamente ao trabalho e concentra esforços para alcançar resultados;

- sabe fixar metas e alcançá-las, luta contra padrões impostos, diferencia-se;

- tem a capacidade de descobrir nichos.

Farah, Cavalcanti e Marcondes (2011) evidenciam as características do empreendedor pontos, sendo: 1) capacidade de assumir riscos; 2) aproveitar oportunidades, tendo iniciativa e força de vontade; 3) busca de informações e conhecimento do ramo empresarial; 4) planejamento e senso de organização; 5) liderança, comprometimento pessoal e otimismo; 6) persistência e espírito empreendedor; e 7) autoconfiança e independência pessoal.

Shane e Venkataraman (2000) acredita que não há consenso na literatura a respeito de uma definição para empreendedorismo, mas este pode ser considerado um processo que envolve três questionamentos: 1) porque, quando e como oportunidades podem ser utilizadas para produzir bens e serviços; 2) porque, quando e como alguns indivíduos descobrem e exploram tais oportunidades e; 3 ) porque, quando e como diferentes modos de ação são utilizados para explorar as oportunidades descobertas.

Degen (2009) ao juntar as ideias de Shaw, Schumpeter e McClelland sobre empreendedorismo, descreve três características essenciais para alguém ser reconhecido como um empreendedor: 1) alguém que não se conforma com os produtos e serviços disponíveis no mercado e procura melhorá-los; 2) alguém que, por meio de novos produtos e serviços, procura superar os existentes no mercado; e 3) alguém que não se intimida com as empresas estabelecidas e as desafia com o seu novo jeito de fazer as coisas.

Nessa mesma linha de raciocínio, Bernardi (2012) destaca um perfil dos empreendedores com as seguintes características: senso de oportunidade, dominância, agressividade e energia para realizar, autoconfiança, otimismo, dinamismo, independência, persistência, flexibilidade e resistência a frustrações, criatividade, propensão ao risco, liderança carismática, habilidade de equilibrar sonho e realização, e habilidade de relacionamento. 
Urge enfatizar que a maioria das características se relaciona diretamente com a personalidade dos empreendedores, o que torna ainda mais relevante as habilidades humanas que envolvem o relacionamento, as negociações e a motivação para um desempenho adequado nas suas atividades.

\section{4 É POSSÍVEL ENSINAR EMPREENDEDORISMO?}

De acordo com Bernardi (2012, p. 64), “há um mito de que não é possível desenvolver o empreendedorismo; deve-se nascer empreendedor. Isso não é verdadeiro, tomando-se por base uma análise mais criteriosa dos vários empreendimentos existentes, independente de sua etapa evolutiva". Nesse sentido, por muito tempo se acreditou que o empreendedor nascia com um diferencial e era predestinado ao sucesso. Entretanto, atualmente, essa visão não existe mais, pois há a crença de que o processo empreendedor pode sim ser ensinado a qualquer pessoa, e que o sucesso é decorrente de vários fatores internos e externos ao negócio, a começar do perfil do empreendedor e de como ele administra as dificuldades enfrentadas no dia-a-dia da empresa.

Marcarini; Silveira; Hoeltgebaum (2003) afirmam que o desenvolvimento do empreendedorismo começa pela educação, em todos os níveis da vida acadêmica. Sendo papel das escolas que buscam formar profissionais gerar pessoas que sejam mais autônomas mais criativas e capazes de liderar.

O ensino do empreendedorismo tem grandes possibilidades de se firmar como prática nas escolas porque a cultura do Brasil é a do empreendedor espontâneo (Filion, 1999). Ele só precisa de estímulo. Segundo este mesmo autor, é necessário que o Brasil promova um programa nacional de educação empreendedora que insira todos os níveis escolares. É preciso preparar os jovens desde o fundamental a desempenharem papéis de empreendedores. Gradativamente vemos os progressos do ensino do empreendedorismo no nosso país, pois, a cada dia veem-se mais instituições de ensino inserindo nas suas matrizes curriculares a disciplina de empreendedorismo.

Há cem anos, a criação de escolas e o fenômeno da educação para as massas tiveram como resultado separar o aprendizado de seu contexto e de sua aplicação prática (Filion, 1999). Hoje, para se ensinar o empreendedorismo é importante que a abordagem leve o aluno a definir e estruturar contextos e compreender várias etapas de sua evolução. (FONSECA JUNIOR e HASHIMOTO, 2014).

É importante lembrar também que a Lei de Diretrizes e Base da Educação, de 20 de Dezembro de 1996, em seu artigo 1ำ, fala que: "A educação abrange os processos formativos que se desenvolvem na vida familiar, na convivência humana, no trabalho, nas instituições de ensino e pesquisa, nos movimentos sociais e organizações da sociedade civil e nas manifestações culturais" (BRASIL, 1996). E ainda acrescenta que, "a educação escolar deverá vincular-se ao mundo do trabalho e prática social"(BRASIL, 1996).

Dessa forma, percebe-se a necessidade da criação de novas formas de ensino e aprendizagem para que os jovens, ao se formarem em um curso de nível médio, técnico ou superior, possam vislumbrar um ambiente que hoje lhes falta - a de não apenas serem empregados sem muita importância e autonomia em uma instituição pública ou privada, mas sim de adotar atitudes inovadoras e porque não de riscos, podendo constituir seu próprio negócio. 
O desafio de levar o propósito do ensino do empreendedorismo para a sala de aula não é fácil, pois segundo Dolabela (1999), o empreendedor é alguém que aprende sozinho. Ele busca os conhecimentos que necessita. Ele faz as coisas acontecerem antecipando-se aos fatos com uma visão futura de negócios porque a ideia do negócio é dele. Assim, um dos deveres do professor é criar um ambiente de ensino que revele e apresente exemplos práticos e concretos de realidades específicas, com personagens e casos de pessoas que possam dizer o que fez e a maneira como desenvolveu suas ações; que fale sobre os problemas e dificuldades que enfrentou. Ensinar e empreender são uma combinação poderosa, porque todo empreendedor é um professor que quer ensinar aos outros, é curioso e quer saber como são e como funcionam as coisas (FONSECA JUNIOR e HASHIMOTO, 2014).

Todavia, ao escrever sobre esse assunto, Dornelas (2012) revela que não há garantia que apenas pelo ensino do empreendedorismo serão gerados novos Bill Gates, Sílvio Santos e Olavo Setúbal, no entanto, sem sombra de dúvidas o ensino ajudará na formação de melhores empresários gerando uma melhoria na qualidade das empresas e uma maior geração de riqueza ao país.

Ainda segundo o mesmo autor, devem-se ficar claro quais são os objetivos do ensino de empreendedorismo, pois esses podem diferir nas diversas universidades e demais instituições de ensino, tal como nas escolas técnicas. Nesse sentido, Dornelas (2012) apresenta alguns pontos importantes a serem explicitados em qualquer ambiente que pretenda focar no ensino do empreendedorismo, a saber: a identificação e o entendimento das habilidades do empreendedor; a identificação e análise de oportunidades; como ocorre a inovação e o processo empreendedor; a importância do empreendedorismo para o desenvolvimento econômico; como preparar e utilizar um plano de negócios; como identificar fontes e obter financiamento para o novo negócio; e como gerenciar e fazer a empresa crescer.

\section{EMPREENDEDORISMO JOVEM}

Assim como o empreendedorismo, encontramos a mesma dificuldade para a definição e delimitação da área (FILION, 1999). Mesmo sem poder definir essa área, pode-se observar o seu florescimento no nosso país, a começar dos interesses e preocupações das instituições de ensino que passam a tornar obrigatória a temática em seus planos de cursos e projetos desenvolvidos sobre $o$ assunto.

Fato é que a cada nova geração pode-se ver que os jovens são cada vez mais marcados por um mundo mais dinâmico e interconectado, gerando assim mais habilidade para executar várias ações ao mesmo tempo, talvez por isso que hoje o Brasil concentra sua força empreendedora na juventude. Segundo Dornelas (2007), não existe um modelo-padrão para que o empreendedor possa ser identificado, apesar de vários autores tentarem defini-los. Portanto, é difícil rotulá-lo. Por outro lado, esse fato mostra que tornar-se empreendedor é algo que pode acontecer a qualquer um e em qualquer idade. Prova disso é que hoje se pode ver que o grupo dominante de empreendedores iniciais brasileiros é formado por jovens adultos entre 25 e 34 anos de idade com 19,2\%. Os dados ainda mostram que entre jovens de 18 e 24 anos, a taxa é de 14,2\%, sendo significativamente maior se comparada à média dos demais países analisados pelo Global Entrepreneurship Monitor (GEM), de apenas 10,7\%. Isto confirma que a população jovem no Brasil 
é relativamente mais ativa no que se refere à atividade empreendedora se comparada a outros países (GEM, 2012).

Todavia, existe uma série de dificuldades que os jovens encontram ao tentar ingressar no mercado de trabalho. Segundo Soares e Machado (2005), inserir o jovem no mercado de trabalho constitui um desafio, sendo o empreendedorismo uma nova dimensão para absorver a mão de obra jovem. Assim, a atividade empreendedora, na criação de um negócio, estabelece-se como alternativa de empregabilidade para o jovem brasileiro e também constituindo mais do que opção de ocupação e desenvolvimento profissional, mas também alternativa para inserção social e oportunidade de estímulo ao desenvolvimento socioeconômico da sociedade. Uma das dificuldades encontradas pelos jovens hoje, são aqueles que privilegiam a formação em detrimento do conhecimento prático encontrando dificuldades para ter sucesso como empreendedores. Cláudia Bittencourt, diretora-geral do Grupo Bittencourt, escreveu no seu site: "Às vezes, eles têm afinidade com o negócio e domina a teoria, mas Ihes falta experiência. 0 empreendedor chega ao mercado com uma sólida formação - MBA, pós-graduação, graduação em escolas de renome, mas nunca trabalhou. Ele acha que vai ser tudo igual ao que aprendeu na escola, mas logo percebe que não é assim." Ainda segundo ela, a inexperiência pode desmotivar esse perfil de empreendedor, o que dificilmente acontece com alguém com experiência. Algumas medidas poderiam prevenir o problema como estagiar no segmento em vista durante o período de formação. Fazendo com que o estudante não só conheça o nicho, mais também se insira dentro dele, assim, o estudante que pretende se tornar empreendedor certamente otimizará os seus estudos graças à experiência prática.

\section{METODOLOGIA}

Esta pesquisa se caracteriza como exploratória-descritiva. Exploratória porque a pesquisa tem como finalidade ampliar o conhecimento a respeito de um determinado assunto; e descritiva porque procura conhecer a realidade estudada, descrevendo com minúcias os fatos e fenômenos observados dessa realidade (TRIVINOS apud ZANELLA, 2006).

O estudo se desenvolveu no IFRN - Campus de Currais Novos, localizado na Rua Manoel Lopes Filho, 773 - Bairro Manoel Salustino - Currais Novos/RN. A população-alvo se constituiu de todos os alunos dos cursos técnicos integrados que cursavam o 4을 ano, nas turmas de informática e alimentos, totalizando 64 alunos, sendo 34 do curso de alimentos e 30 do curso de informática. Nesse sentido, esta pesquisa se caracteriza como uma pesquisa do tipo censitária. Sobre pesquisa censitária, Zanella (2006) enfatiza que esse tipo de pesquisa não deve se utilizar a amostragem. Como instrumentos de coleta de dados, utilizou-se a observação direta intensiva e a aplicação de questionário.

No tocante a técnica de observação direta intensiva, essa pode ser realizada através de duas modalidades: observação e entrevista. A observação utilizada nesse artigo "é uma técnica de coleta de dados para conseguir informações e utiliza os sentidos na obtenção de determinados aspectos da realidade" (MARCONI e LAKATOS, 2010, p. 173). Segundo Ander-Egg (1978) existem quatro tipos de observador, dentre eles o observador segundo a sua participação, podendo ser participante ou não participante. Utilizamos a observação participante, que "consiste na participação real do pesquisador na comunidade ou grupo" (MARCONI E LAKATOS, 2010, p. 177). 
O método da observação nos permitiu obter informações de natureza verbal e não verbal, como forma de contribuição para o conhecimento científico no campo do ensino do empreendedorismo para os jovens nos bancos escolares. Foram seguidos os seguintes passos: definir os objetivos de estudo; decidir sobre o grupo de sujeitos a observar; legitimar a presença junto ao grupo a observar; observar e registrar notas de campo durante sete meses; e analisar os dados.

Vale salientar que ao término do projeto ora descrito, foram aplicados questionários com alunos através de perguntas abertas com ênfase o referido projeto de extensão. Por fim, as análises dos dados foram estritamente qualitativas.

\section{RESULTADOS E DISCUSSÕES}

Buscando atender a necessidade de inserção do jovem estudante no mercado de trabalho e mais precisamente na sua área de formação, o Projeto de Extensão "Empreendedorismo Jovem: da escola para o mercado de trabalho" com suas diversas ações proporcionou aos mais de 60 alunos concluintes do nível técnico integrado em alimentos e informática, observar, experimentar e indagar sobre o cotidiano de empresas nesses segmentos por meio de trocas de experiências significativas para o processo de ensino-aprendizagem desses alunos, bem como para 0 fortalecimento da relação entre instituição de ensino e mercado de trabalho.

Dentre os resultados observados, destacam-se os abaixo descritos:

- Maior integração teoria e prática, os alunos perceberam as potencialidades de determinados negócios da região, além de conhecerem a realidade interna das empresas visitadas, o que facilitou consideravelmente o desenvolvimento das empresas fictícias (Hotel de Projetos), que fazem parte de uma ação de ensino diferenciada utilizada como projeto de fim de ano da disciplina de gestão organizacional nas turmas acima descritas;

- Houve uma maior percepção dos alunos em relação aos negócios provenientes da região do Seridó, pois, muitas vezes os alunos possuem uma visão "míope" de que ao término dos seus cursos técnicos (alimentos e/ou informática), os mesmos só possam atuar e desenvolver suas habilidades em regiões metropolitanas ou na capital do estado. Observar e compreender as potencialidades da região através das empresas já existentes foi uma excelente oportunidade de reflexão para o futuro desses profissionais;

- Percebeu-se que através das visitas e palestras, houve um maior interesse sobre o assunto por parte dos alunos, bem como pela valorização da sua profissão enquanto futuros técnicos. Os vários depoimentos dos alunos demostraram o quanto foi interessante a dinâmica do projeto e o aumento do interesse desses alunos quanto o assunto era empreendedorismo, inovação, mercado de trabalho e negócios;

- Em muitos empreendimentos, os alunos observaram a falta de técnicos em alimentos e informática, possibilitando aos mesmos perceberem oportunidades de atuação profissional, além dos percalços enfrentados por esses profissionais, quando em diversas regiões e/ou localidades, estes não são valorizados ou sequer procurados. Isso ficou mais evidente nas empresas relacionadas a área de alimentos. Houve, inclusive, algumas inferências dos alunos em algumas visitas sobre o assunto, isto é, os mesmos evidenciavam aos responsáveis pelas empresas a importância de se ter um profissional qualificado na área para atuar de maneira mais adequada, mais técnica, e conforme aos padrões exigidos pelos órgãos regulamentadores. 
A ideia do projeto não foi necessariamente observar grandes empreendimentos, mas casos simples como o de "Seu Dedé do Alumínio" da cidade de Acari/RN que recondiciona panelas de pressão velhas ou inutilizadas, transformando-as em caçarolas. Nesse sentido, o exemplo de Seu Dedé gerou um impacto considerável na visão dos alunos sobre o empreendedorismo. De maneira semelhante, a palestra com o ex-aluno do IFRN - Campus Currais Novos, o empresário e fundador da TAG Criativa - empresa do ramo de informática (programação, mídias sociais, designer gráfico, desenvolvimento web, etc) de Currais Novos; a palestra com Siderley Jatobá da Sidy's TV a Cabo empresa destaque e exemplo de inovação e ousadia no ramo da comunicação no Nordeste; a palestra com Carlos Augusto da Polpa de Frutas Seridó em Cruzeta/RN; e em especial a visita ao Porto Digital em Recife/PE.

Todas essas visitas/palestras foram momentos vivificantes em que o empreendedorismo tornou-se prática e realidade na percepção dos alunos envolvidos no projeto. Urge enfatizar que esses exemplos apresentados influenciaram significativamente os trabalhos/seminários propostos quanto à criação de empresas fictícias pelo professor da disciplina de Gestão Organizacional e coordenador do projeto junto aos alunos dos cursos técnicos integrado em informática e alimentos.

Além do mais, fica evidente que a formação de um empreendedor com maiores possibilidades de obter êxito nos seus projetos pessoais e/ou empresariais, passa também por meio de um contato mais intenso com o mercado, isto é, com referências de empresários nos mais diversos segmentos. Além do mais, essas observações e trocas de informações permitem um olhar mais atento aos possíveis desafios, demandas e oportunidades de negócios. As experiências de visitas e palestras com empresários (independentemente do porte da empresa) foram significativas para a construção do saber e das competências exigidas atualmente.

Nessa perspectiva, o projeto aqui descrito ofereceu de forma satisfatória algumas ferramentas que auxiliam no processo de ensino-aprendizagem desses alunos, preenchendo lacunas identificadas na formação do jovem e futuro empreendedor. Assim, através dos resultados observados no projeto, diversos alunos tiveram a possibilidade de perceber com clareza o segmento de mercado relacionado à sua formação técnica (informática ou alimentos), a partir do contato com empresas locais e regionais.

\section{CONSIDERAÇÕES FINAIS}

Finalmente, entende-se que o ensino do empreendedorismo em prol da formação de jovens empreendedores é importante e necessário para o desenvolvimento da economia do Brasil, haja vista que o Global Entrepreneurship Monitor (GEM) através de relatório com dados de 2012, mostra que $14,2 \%$ dos empreendedores iniciais brasileiros são jovens.

Sendo assim, percebe-se a relevância de projetos como o que aqui foi descrito, em busca de proporcionar formação e subsídios para jovens que estão estudando em nível médio, técnico ou superior, haja vista que na maioria das vezes, estes não conseguem enxergar a dinâmica do mercado de trabalho e vislumbrar oportunidades de novos negócios. Aliás, muitos não conseguem superar facilmente as dificuldades que surgem no ingresso a esse mercado tão competitivo e exigente, principalmente no que tange a não percepção de uma clara integração entre o que foi estudado em sala de aula e as situações reais existentes numa empresa. 
Como consequências desse contato com o ramo de negócio, observou-se que os alunos obtiveram um melhor entendimento das potencialidades de um futuro negócio na sua área de formação, tal como adquiriram uma melhor e maior integração entre a teoria e prática.

Outro fator importante identificado no projeto foi à percepção dos alunos quanto ao potencial de desenvolvimento de negócios de pequeno porte em cidades do interior como Currais Novos, Acari e Cruzeta (interior do RN, mas especificamente localizadas na região do Seridó), o que pode trazer resultados interessantes em relação ao desenvolvimento local e regional, diminuindo a "migração" desses alunos - futuros profissionais - para capitais ou grandes centros urbanos.

Destaca-se, ainda, que esse estudo teve um número restrito de participantes, isto é, apenas duas turmas concluintes do ensino médio integrado. Nesse sentido, esse estudo não permite generalizações em relação às conclusões obtidas, sendo esta uma das principais limitações desse trabalho.

Desse modo, seria interessante que outras pesquisas fossem realizadas com intuito de observar a percepção desses alunos sobre empreendedorismo analisando as diferenças entre os cursos existentes no IFRN - Campus Currais Novos (alimentos e informática), utilizando um período mais longo, ou seja, turmas que cursaram a disciplina Gestão Organizacional no período de 4 ou 5 anos (isso certamente aumentaria o número de participantes da pesquisa); estudos que analisem não só as turmas do ensino médio integrado, mas também as turmas do nível superior (cursos de tecnologia), ensino médio na modalidade subsequente, e ensino médio na modalidade da educação de jovens e adultos; e por fim, pesquisas que analisem esse processo de ensino-aprendizagem em diversos campi da instituição.

\section{REFERÊNCIAS BIBLIOGRÁFICAS}

1. ANDER-EGG, Ezequiel. Introducción a las técnicas de investigación social: para trabajadores sociales. 7. ed. Buenos Aires: Humanitas, 1978.

2. BERNARDI, Luiz Antonio. Manual de Empreendedorismo e Gestão: Fundamentos, Estratégias e Dinâmicas. São Paulo: Atlas, 2012.

3. BRASIL. Leis de Diretrizes e Bases da Educação, 1996. Disponível <www.mec.org.br>. Acesso em: 15/05/2014.

4. BRASIL, Sandra Aparecida; BRASIL, Cintia Fernanda; NOGUEIRA, Clariana Ribeiro. Empreendedorismo Jovem: Fatores que Contribuem para a Atividade Empreendedora. Universidade Estadual de Maringá. Caderno de Administração, v.21, n.2, 2013.

5. BULGACOV, Yára Lúcia M. Bulgacov, et. al. Jovem empreendedor no Brasil: a busca do espaço da realização ou a fuga da exclusão? Revista de Administração Pública, v. 45, n. 3, 2010.

6. CARRETEIRO, T.C. A doença como projeto: uma contribuição à análise de formas de afiliações e desfiliações sociais. In: SAWAIA, B. (Org.). As artimanhas da exclusão: análise psicossocial e ética da desigualdade. São Paulo: Vozes, 2001, p. 87-116.

7. DEGEN, Ronald Jean. O Empreendedor: empreender como opção de carreira. São Paulo: Pearson Prentice Hall, 2009.

8. DOLABELA, Fernando. O Ensino de Empreendedorismo no Brasil: Uma Metodologia Revolucionária. São Paulo: Fundação Vanzolino, 1999. 
9. DORNELAS, José Carlos Assis. Empreendedorismo na prática: mitos e verdades do empreendedor de sucesso. Rio de Janeiro: Elsevier, 2007.

10.

Empreendedorismo: transformando ideias em negócios. 4. ed. Rio de Janeiro: Elsevier, 2012.

11. DRUCKER. Peter Ferdinand. Inovação e Espírito Empreendedor: Prática e Princípios. São Paulo: Cengage Learning, 2012.

12. FARAH, Osvaldo Elias; CAVALCANTI, Marly; MARCONDES, Luciano Passos. Empreendedorismo Estratégico: Criação e gestão de pequenas empresas. São Paulo: Cengage Learning, 2011.

13. FILION, L. J. Empreendedorismo: empreendedores e proprietários-gerentes de pequenos negócios. Revista de Administração, v. 34, n. 2, 1999. Disponível em: http://www.dge.ubi.pt/msilva/OE_OGE/Empreendedorimo.pdf. Acesso em: 12/05/ 2013.

14. FONSECA JUNIOR, Ranulfo Soares da; HASHIMOTO, Marcos. A Importância do Ensino Empreendedor na Formação de Nível Técnico. In: VII Encontro de Estudos sobre Empreendedorismo e Gestão de Pequenas Empresas (EGEPE), Anais..., Goiânia: 2014.

15. GLOBAL ENTREPRENEURSHIP MONITOR. Empreendedorismo no Brasil. Relatório Global, 2012. Disponível em: <http://www.gemconsortium.org>. Acesso em: 12/05/2014.

16. LIMA-FILHO, D. O.; SPROESSER, R. L.; MARTINS, E. L. C. Empreendedorismo e Jovens Empreendedores. In: Revista de Ciências da Administração, v. 11, n. 24, mai/ago - 2009, p. 246-277. Disponível em: https://periodicos.ufsc.br/index.php/adm/article/view/21758077.2009v11n24p246/12623. Acesso em: 12/05/ 2014.

17. MARCONI, Marina de Andrade; LAKATOS, Eva Maria. Fundamentos de Metodologia Científica. 4. ed. São Paulo: Atlas, 2010.

18. RIO GRANDE DO NORTE. Lei no 11.892, de 29 de dezembro de 2008 Institutos Federais: comentários e reflexões. Natal: IFRN, 2009.

19. SHANE, S.; VENKATARAMAN, S. The promise of entrepreneurship as a Field of research. In: Academy of Management Review, v. 25, n. 1, 2000, p.217-226. Disponível em: www.jstor.org/discover/10.2307/259271 ?uid=3737664\&uid=2129\&uid=2\&uid=70\&uid=4\&s id=21102539411073. Acesso em: 12/05/2014.

20. SOARES, M. A. F.; MACHADO, H. P.V. Jovens empreendedores: perfil, dificuldades na gestão e perspectivas dos empreendimentos. In: $V$ Encontro de Estudos sobre Empreendedorismo e Gestão de Pequenas Empresas (EGEPE), Anais..., Curitiba, 2005.

21. WAISELFISZ, J. J. Juventude, violência e cidadania: os jovens de Brasília. São Paulo: Cortez, 1998.

22. ZANELLA, Liane Carly Hermes. Metodologia da pesquisa. Florianópolis: SEAD/UFSC, 2006.

23. ZOUAIN, Deborah Moraes; DE OLIVEIRA, Fátima Bayma; BARON, Francisco Marcelo. Construindo o perfil do jovem empreendedor brasileiro: relevância para a formulação e implementação de políticas de estímulo ao empreendedorismo. Revista de Administração Pública, v. 41, n. 4, 2007. 